\title{
Why do men with urethritis in Cameroon prefer to seek care in the informal health sector?
}

\author{
F Crabbé, H Carsauw, A Buvé, M Laga, J P Tchupo, A Trebucq
}

Objective: To study the impact of cost of treatment for sexually transmitted diseases (STDs) on the preference of men with urethritis to seek care in the informal sector.

Subjects and methods: A random sample of young men from the general population of Yaoundé and Douala, Cameroon, and of employees of a Yaoundé factory underwent a structured interview on the occurrence of STD-related complaints and health seeking behaviour. Men who consulted in the formal sector were compared with men consulting in the informal sector, with regards to cost of medication and level of education.

Results: Sixteen percent of men in the general population and $20 \%$ of factory employees reported a history of urethritis in the 12 months preceding the interview. Of the men in the general population $53 \%$ had sought care in the formal sector; among the factory employees this proportion was $56 \%$. Men who did not consult in the formal sector spent significantly less on drugs than men who did consult in the formal sector: median cost $\$ 14.4$ versus $\$ 24.0(p=0.02)$ for drugs purchased in pharmacies; median cost $\$ 8$ versus $\$ 32$ for drugs purchased in small stores or from acquaintances. Preference for formal health services was associated with higher educational attainment.

Conclusion: In large towns in Cameroon the utilisation of formal health services for STD related complaints is low and the high cost of treatment in the formal sector may play an important role in the choice of care option.

(Genitourin Med 1996;72:220-222)

Keywords: urethritis; Cameroon; health seeking behaviour; men

\section{Introduction}

Prompt and effective treatment of sexually transmitted diseases (STDs) prevents complications and sequelae in individual patients and reduces the transmission of STDs by decreasing the duration of infectiousness. As such STD case detection and management is an essential component of any STD control programme.

The effectiveness of STD case management by health services depends in part on the sensitivity of the diagnostic process and the efficacy of the treatment offered. Another critical determinant of the effectiveness of STD case management is the coverage of curative services for STDs, that is, the proportion of STD infections occurring in the population that are presented to these services. ${ }^{1}$ Studies on health care seeking behaviour for STDs suggest that the coverage of formal health services is rather low in sub-Saharan Africa. In Mwanza Region, Tanzania, $67 \%$ of men and $55 \%$ of women consult public health facilities for STD related complaints. ${ }^{2}$ A study conducted by the Organisation de Coordination pour la Lutte contre les Endémies en Afrique Centrale (OCEAC) found that roughly $50 \%$ of young men in large cities sought care for their urethritis in the formal health sector. ${ }^{3}$ Whether or not patients consult in the formal sector depends, broadly speaking, on service characteristics (that is, accessibility, affordability and acceptability); patient characteristics; and the socio-cultural environment.

Using data of the above mentioned OCEAC study we examined in how far cost of treatment for STDs in the formal sector com- pared with the informal sector may be an important factor in determining why men with urethritis prefer to seek care in the informal sector.

\section{Methods}

Between October 1991 and March 1992, a series of surveys has been carried out by the OCEAC among men in Yaoundé and Douala, the two largest cities of Cameroon. The objective of these surveys was to provide baseline information on knowledge and practices in relation to STDs and AIDS, more especially on health seeking behaviour for STDs and on STD case management. The methods have been described in detail elsewhere. ${ }^{3}$ We used the data from the two community based surveys and the survey among factory employees. The community based surveys were conducted in Yaoundé and Douala. Men aged 18 to 30 years were selected from the general population by random cluster sampling and were interviewed on socio-economic characteristics, occurrence of signs and symptoms of STDs and health care seeking behaviour, including cost of treatment. The survey among company employees included all men up to the age of 40 years who presented themselves for their annual check-up at one company in Yaoundé. The same questionnaire was used as in the general population survey.

For reasons of reliability we only analysed data on urethritis episodes that occurred in the 12 months preceding the interview. We assessed the proportion of men who consulted in the formal sector vs the proportion who con- 
Table 1 Site of first encounter

\begin{tabular}{|c|c|c|}
\hline Site of first encounter & $\begin{array}{l}\text { General population (\%) } \\
n=186\end{array}$ & $\begin{array}{l}\text { Factory employees (\%) } \\
n=55\end{array}$ \\
\hline $\begin{array}{l}\text { Formal sector } \\
\text { Public health centre } \\
\text { Private practitioner } \\
\text { Company clinic } \\
\text { Self Medication } \\
\text { Informal sector } \\
\text { Pharmacy } \\
\text { Traditional healer } \\
\text { Small store } \\
\text { Other }\end{array}$ & $\begin{array}{l}98(53 \%) \\
73(39 \%) \\
25(13 \%) \\
-30(16 \%) \\
58(32 \%) \\
15(8 \%) \\
12(7 \%) \\
3(2 \%) \\
28(15 \%)\end{array}$ & $\begin{aligned} & 31(56 \%) \\
& 7(13 \%) \\
& 5(9 \%) \\
& 19(35 \%) \\
& 8(15 \%) \\
& 16(30 \%) \\
& 2(4 \%) \\
&- \\
&-14(26 \%)\end{aligned}$ \\
\hline
\end{tabular}

${ }^{\star}$ Mainly friends and acquaintances.

sulted in the informal sector. For the purpose of this study we defined "formal sector" as public health centres and private practitioners. Patients purchasing drugs from a pharmacy without prescription were considered as consulting in the informal sector, as pharmacies are not officially allowed to deliver antibiotics without prescription. Data of medication cost have been briefly presented elsewhere. ${ }^{3}$ We further explored these data and compared expenses incurred by men who consulted in the formal sector versus men who did not seek care in the formal sector. Lastly we explored whether there exists any association between level of education, as a proxy measure of socio-economic status, and preference for the formal or the informal sector. All analyses were carried out using EPINNFO. As costs of medication showed a skewed distribution, non-parametric tests were used to test the significance of differences in costs between different groups.

\section{Results}

In Yaounde 607 men from the general population were interviewed and in Douala 572. As the interviewees in the two towns were similar with regards to socio-economic characteristics, incidence of urethritis and health seeking behaviour, data from both groups were combined. Of the 1179 men interviewed 189 (16\%)

Table 2 Site of purchase of drugs and expenditure

\begin{tabular}{lllr}
\hline Site of drug purchase & $\begin{array}{l}\text { General population } \\
n=85\end{array}$ & $\begin{array}{l}\text { Median cost in } \mathbf{s} \\
n=81\end{array}$ & Range \\
\hline Pharmacy & $52(61 \%) \dagger$ & 20 & $1-320$ \\
Consulted in formal & $33(39 \%)$ & $24 \cdot 0 \ddagger$ & $5 \cdot 8-320$ \\
$\quad$ sector first & $19(22 \%)$ & $14 \cdot 4 \ddagger$ & $1 \cdot 0-60$ \\
Did not consult & $5(6 \%)$ & $6 \cdot 0$ & $4 \cdot 8-56$ \\
Health centre & $3(33 \%) \dagger$ & $8 \cdot 0$ & $0-64$ \\
Small store or acquaintances & $3(4 \%)$ & $32 \cdot 0$ & $26-64$ \\
Consulted in formal & $25(29 \%)$ & $8 \cdot 0$ & $0-48$ \\
sector first & & & \\
\hline
\end{tabular}

${ }^{\star}$ Men from Douala only.

tKruskall-Wallis test: $\mathrm{p}=0.0006$

†ilcoxon two-sample test: $p=0.02$

Table 3 Association between level of education and choice of care option

\begin{tabular}{llll}
\hline & $\begin{array}{l}\text { Preference for } \\
\text { formal sector }\end{array}$ & $\begin{array}{l}\text { Preference for } \\
\text { informal sector }\end{array}$ & $\begin{array}{l}\text { Odds ratio } \\
(95 \% \text { CI) }\end{array}$ \\
\hline $\begin{array}{l}\text { General population } \\
\text { High education }\end{array}$ & $88(57 \%)$ & $66(43 \%)$ & $2 \cdot 7$ \\
$\begin{array}{l}\text { Low education } \\
\begin{array}{l}\text { Company employees } \\
\text { High education }\end{array}\end{array}$ & $10(33 \%)$ & $20(67 \%)$ & $(1 \cdot 1-6 \cdot 6)$ \\
Low education & $26(62 \%)$ & $16(38 \%)$ & $\begin{array}{l}2 \cdot 7 \\
(0 \cdot 6-11 \cdot 8)\end{array}$ \\
\hline
\end{tabular}

reported at least one episode of urethritis in the year preceding the interview. Among the 299 company employees $59(20 \%)$ had at least one episode of urethritis.

\section{Site of first contact and site of purchase of treatment}

Of the 189 men in the general population who had an attack of urethritis in the previous year $16 \%$ reported that they had resorted to self medication. Among the company workers this percentage was $15 \%$. The remaining interviewees reported seven different options as first site for seeking care or advice (see table 1). Overall $52 \%$ of the men in the general population and $57 \%$ of the company employees consulted in the formal sector.

Data on the site of purchase of medication and on costs were available for the men of Douala and the company employees only. Of the 85 men from Douala who had an episode of urethritis in the preceding year, $42(61 \%)$ obtained medication from a pharmacy, $5(6 \%)$ received it at a health centre and $28(33 \%)$ bought drugs in a store or obtained them from an acquaintance. Men who first consulted in the formal sector more often purchased drugs from the pharmacy than men who did not consult in the formal sector $(81 \% v 43 \%)$. Among the company employees the majority obtained their treatment from a pharmacy; only 1 man reported having received treatment at a health centre.

\section{Cost of medication}

For 82 men who had consulted in the formal sector the median expenditure on drugs was $\$ 24$ (range 1-320); for 71 men who had not consulted in the formal sector it was $\$ 10$ (range 0-120). This difference was significant (Wilcoxon two-sample test: $p<0.001$ ). Among the men who had consulted in the formal sector there was no statistically significant difference in expenditure between men who went to a public health centre and men who saw a private practitioner (median expenditure: $\$ 26 v \$ 20$ ).

More detailed information on costs of medication in relation to the site where the drugs were purchased was available for the men from Douala only (see table 2). Drugs obtained from a pharmacy were more expensive than drugs purchased in a small store or obtained from a health centre. Among the men who purchased drugs at a pharmacy, men who had consulted in the formal sector spent more than men who had not consulted in this sector (median expenditure: $\$ 24.0$ v $\$ 14.4$; Wilcoxon two-sample test: $\mathrm{p}<0.02)$.

\section{Level of education and care preference}

Data on education were available for 186 men out of the 189 from the general population sample who had a urethritis in the previous year. Of these, $154(83 \%)$ had attended at least secondary school and were classified as "high educational level". Among the company employees this proportion was 42 out of 55 $(76 \%)$. Men of higher educational attainment were more likely to consult in the formal sector than men with lower education (see table 3 ). 


\section{Discussion}

There is now strong evidence for a facilitating role of so-called "classic" STDs in the transmission of HIV infection, and STD control is considered one of the most important interventions to slow down the spread of HIV infection. ${ }^{45}$ By reducing the duration of infectiousness and thus interrupting the chain of transmission, prompt and effective treatment of STDs can lead to a decrease in the incidence and prevalence of STDs, provided there is a high coverage of STD patients by services that offer effective treatment.

Formal health services are in principle best placed to provide effective treatment for STDs. However the OCEAC study found that only about half of the men in Yaoundé and Douala sought care for their urethritis in the formal health sector. This finding is in line with data from other research in sub-Saharan Africa which suggest that a high proportion of patients with STDs never seek care in the formal sector or only attend formal health services after alternative treatments have failed. Sjaak van der Geest in his study on self-care in South Cameroon lists four main reasons for purchasing drugs in the informal sector (including pharmacies if the drugs are obtained without prescription): (1) drugs from vendors are more affordable; (2) drug vendors are more accessible; (3) little shops have more flexible opening hours than health services; (4) the social distance between patients and drug vendors may be smaller than between patients and health care professionals. ${ }^{6}$ Van der Geest's study dealt with disease in general. STDs however are a rather special group of diseases, because they are often associated with feelings of shame and for STDs there may be additional reasons for not consulting in the formal sector. For instance, in a study on health care seeking behaviour conducted in Swaziland embarrassment has been revealed as a reason for not attending a health centre. ${ }^{7}$ In Malawi traditional healers were preferred because they are more sympathetic and it is felt that confidentiality is better assured. ${ }^{8}$ The informal sector may thus also be preferred because less questions are asked or because privacy is felt to be better assured.

The findings of our study suggest that in Yaoundé and Douala financial constraints may be an important factor in the decision not to consult in the formal sector. The median expenditure on drugs when seeking care at formal health services was more than twice the median expenditure in the informal sector, $\$ 24 v$ $\$ 10$. In general, in Cameroon, drugs are not available in public health centres, as evidenced by the fact that in our study only five out of the 41 men in Douala who consulted in the formal sector, obtained their medication from a health centre. Patients usually receive a prescription and are referred to a pharmacy to purchase their medication. This explains the high expenditure on drugs, but also the lack of difference in expenditure between men who went to a public health centre and men who saw a private practitioner. On the other hand, the difference in expenditure at the pharmacy between men who had consulted in the formal sector and men who had not, can be explained by the fact that men who had not consulted in the formal sector felt free to choose less expensive drugs and/or to buy an incomplete treatment regimen. The association that was found between high level of education and use of the formal sector also points towards socio-economic factors playing an important role in the choice of care. In this study, however, it was not possible to examine separately purchasing power and education per se as factors determining the choice of care option.

An exit survey at pharmacies, conducted in 1992, found similar high expenditures on drugs, the median expenditure being $\$ 21$ in Douala and $\$ 18$ in Yaoundé. ${ }^{9}$ Moreover it was found that a large variety of antibiotics were prescribed but that an estimated 50 to $75 \%$ of the patients received a prescription that would not cure their urethritis. ${ }^{9}$ Thus, considering that half of the men consult the formal health sector, of which only about half obtain an effective treatment, it can be estimated that in Yaoundé and Douala not more than $30 \%$ of cases of urethritis were cured by health services. Low utilisation of the formal health sector for STDs is a problem, which should be considered in relation to the quality of the services offered. This study and the exit survey reported by Trebucq et al have demonstrated that it does not make sense for instance to encourage patients with STDs to consult in the formal health sector, unless patients consulting in that sector receive effective and affordable treatment. Formal and informal health services should be considered as services that are competing for the same market. "Consumers" prefer the informal health sector for good reasons and a clear understanding of these reasons is a prerequisite for improving the utilization of formal health services.

This work was funded in part by the United States Agency for International Development as part of Family Health International's AIDS Control and prevention Project (AIDSCAP), contract $n^{\circ}$ 623-0238-A-00-4031-00.

The content of this report does not necessarily reflect the views or policies of the USAID.

1 A Buvé, M Laga, F Crabbé, et al. A model for the operational assessment of case detection and management of STDs. 8th. International Conference on AIDS in Africa, Marrakech 1993. Abstract no WRT 015.

2 J Newell, K Senkoro, F Mosha, et al. A population-based study of syphilis and sexually transmitted disease syndromes in north-western Tanzania. 2. Risk factors and dromes in north-western Tanzania. 2. Risk factors and

3 JP Louis, R Migliani, A Trebucq, et al. Prise en charge des Maladies Sexuellement Transmissibles au Cameroun en milieu urbain, en 1992. Ann Soc Belge Méd Trop 1993, 73:267-78

4 M Laga, M O Diallo, A Buvé. Inter-relationship of sexually transmitted diseases and HIV: where are we now? AIDS 1994;8(suppl 1):S1 19-S24

5 World Development Report 1993. Investing in Health Published for the World Bank. Oxford University Press, 1993:p115.

6 Van der Geest S. Self-care and the informal sale of drugs in South Cameroon. Soc Sci Med 1987;25:293-305.

Green EC. Sexually transmitted disease, ethnomedicine and health policy in Africa. Soc Sci Med 1992;35:121-30.

8 Helitzer-Allen D, Allen H. Focused ethnographic study of sexually transmitted illnesses in Thyolo, Malawi. Report

9 Trebucq A, Louis JP, Tchupo JP, Migliani R, Smith J, Delaporte E. Treatment regimens of STD patients in Cameroon: a need for intervention. Sex Transm Dis 1994; 21:124-6. 